\title{
Professional choice self-efficacy: predicting traits and personality profiles in high school students
}

\author{
Rodolfo Augusto Matteo Ambiel ${ }^{*}$ and Ana Paula Porto Noronha
}

\begin{abstract}
This study aimed to verify the predictive capacity of the Big Five personality factors related to professional choice self-efficacy, as well as to draw a personality profile of people with diverse self-efficacy levels. There were 308 high school students participating, from three different grades (57.5\% women), from public and private schools, average 26.64 years of age. Students completed two instruments, Escala de Autoeficácia para Escolha Profissional (Professional Choice Self-efficacy Scale) and Bateria Fatorial de Personalidade (Factorial Personality Battery). Results were obtained using multiple regression analysis, analysis of variance with repeated measures profile and Cohen's $d$ to estimate the effect size of differences. Results showed that Extraversion, Agreeableness and Conscientiousness were the main predictors of self-efficacy. Differences from medium to large were observed between extreme groups, and Extraversion and Conscientiousness were the personality factors that better distinguish people with low and high levels of self-efficacy. Theses results partially corroborate with the hypothesis. Results were discussed based on literature and on the practical implications of the results. New studies are proposed.
\end{abstract}

Keywords: Psychological assessment, Career counseling, Social cognitive theory, Personality traits

\section{Background}

The Social Cognitive Theory of Career Development (TSCDC), postulated by Lent et al. (1994), based on Bandura (1977), and Hackett and Betz (1981), provides an explanatory model of three independent, yet interconnected, processes on career-related decisions. The first one is the development of professional interests. This variable defined by Lent et al. (1994) as standards of preference, indifference or aversion to professional activities, would be the result of a series of life experiences since childhood, tending to stabilize in late adolescence, while socio-cultural, educational, biological and personality aspects would be auxiliary in such process.

The second process described by Lent et al. (1994) regards academic and career choices. People tend to develop a sense of competence to perform in certain fields based on their preferences and to expect certain consequences, respectively named self-efficacy beliefs and outcome expectations. Based on the influences of environmental and contextual conditions, a person

\footnotetext{
* Correspondence: rodolfo.ambiel@usf.edu.br
}

Universidade Sao Francisco, Itatiba, Brazil develops their goals and has effective behaviors of choice, engaging in information search tasks and taskplanning future actions.

Finally, the third process seeks to explain the engagement in academic and professional activities in a continuum from previous processes. It is noteworthy that by going through new experiences, a feedback loop of the model may occur, since changes in academic and work conditions may favor the development of new interests, self-efficacy beliefs and outcome expectations.

Especially in relation to self-efficacy, Bandura (1986) defined it as a person's own beliefs regarding his or her own ability to plan and perform courses of action related to specific areas. Thus, the construct has been applied to the career development context and has been mainly related to the type of interest of Holland (Nunes and Noronha 2008, 2011; Turner et al. 2010; among others) and with career decisions (examples: Taylor and Betz 1983; Betz and Taylor 2012; Miguel et al. 2013; Isik 2012; Choi et al. 2012).

Self-efficacy for career-related decisions refers to people's beliefs in their own capabilities to engage in tasks 
related to their choice and professional decisions. The evaluation of the construct can be accomplished, for example, through the Career Decision Self- Efficacy Scale (CDSE - Betz and Taylor 2012), both in their complete form (50 items) and the reduced version (25 items). Despite a series of controversies regarding its internal structure (Chaney et al. 2007; Creed et al. 2002; Hampton, 2006; Luzzo 1993; Peterson and Delmas 1998; Ramírez and Canto 2007; Taylor and Betz 1983; Watson et al. 2001), CDSE assessment is based on five subscales, named Accurate Self-Appraisal, Gathering Occupational Information, Goal Selection, Future Planning and Problem Solving. The concurrent use of such subscales generates a total score. In literature references can be found on the use of CDSE to evaluate counseling processes (Reese and Miller 2006) and correlational studies with indecision (Gati et al. 2013), sociodemographic variables (Stacy 2003), vocational interests (Srsic and Walsh 2001; Breeding 2008) and personality (Hartman and Betz 2007; Jin et al. 2009; Page et al. 2008).

In Brazil, Ambiel and Noronha (2012) built the Professional Choice Self-efficacy Scale (EAE-EP, from Portuguese acronym), based on the literature on CDSE, whose results showed psychometric adequacy for evaluation of four factors, namely, Self Appraisal, Gathering Occupational Information, Practical Professional Information Search and Future Planning (Ambiel et al. 2015). The structure of EAE-EP was considered partially similar to CDSE since it does not rely on factors related to the selection Goals and Problem Solving, and one of EAE-EP of factors, Practical Professional Information Search, is not present in the CDSE independently, composed by items related to the ability of interpersonal contacts (ie, visits, conversations) to get information about the professions or courses, establishing itself as a specificity of the Brazilian instrument.

As far as personality is concerned, it has been one of the most researched variables in the career development context, with results pointing to its predictive capacity of both the choice as well as the involvement and performance at work (Cupani and Pérez 2006; Rogers and Creed 2010; Nauta 2007; Wille and De Fruyt 2014; Woods et al. 2013; Zacher, 2014). Based on the theories about personality Wille and De Fruyt 2014; point out that the Big Five model has remained as the most researched one in the vocational and career counseling field.

This theoretical model has been investigated since the 1930s, accumulating a considerable amount of studies around the world in such a way that authors have hypothesized on the universality of the model (Pulver et al. 1995; Soto et al. 2011). In Brazil, two instruments based on Big Five are more frequent in research, namely, the Brazilian version of the NEO-PI (Costa and McCrae 1992), which has predominantly been studied in clinical settings (Silva and Maia 2013;
Carvalho et al. 2014) and the Personality Factor Battery (BFP, from Portuguese acronym; Nunes et al. 2010), which includes studies with adolescents in professional choice processes (Ambiel et al. 2012; Nunes and Noronha 2009). In BFP, one of the instruments used in this study, the factors have been denominated Neuroticism, Conscientiousness, Openness to Experience, Extraversion and Agreeableness, and they evaluate, respectively, the level of adjustment and emotional instability; organization, persistence, motivation and responsibility to achieve objectives; exploratory behavior and appreciation of new experiences; level of social interaction in terms of quantity and intensity; and type of social interaction that varies in a continuum of compassion to antagonism.

In the context of TSCDC, Larson and Borgen (2006) argue that personality is inserted as a personal factor that precedes the development of self-efficacy. The authors mention that, despite the secondary role that was given to personality in TSCDC, several studies have found relationships between traits and self-efficacy, suggesting the role of personality as a mediator of career choices and the development of interests (Cupani and Pérez 2006). As for self-efficacy, relationships with negative Neuroticism and positive Extraversion and mainly with Conscientiousness seem to be empirically well-founded (Hartman and Betz 2007; Page et al. 2008; Rogers and Creed 2010), while positive correlations are also found, albeit low, with Agreeableness (Jin et al. 2009; Ourique and Teixeira 2012).

Literature on TSCDC, particularly on self-efficacy for career decisions, has been limited to the study of personality characteristics as predictors of selfefficacy, but it is still not known properly which traits differentiate people with different levels of beliefs in ability to engage in tasks related to professional choice. In this sense, the present study, in addition to seeking to expand the knowledge on the profiles of people with different levels of self-efficacy, is justified by the fact that there are few studies in the literature relating self-efficacy with personality for teenagers in the context of professional decisions. Particularly in Brazil, the only research found studying this relationship took place with higher education students (Ourique and Teixeira 2012) and, therefore, this study may help in the aquisition of knowledge on the diagnosis in career guidance processes.

Thus, this research has the primary objective to test the Big Five factors as predictors of self-efficacy for professional choice in a sample of Brazilian students in high school. It also seeks to verify the differentiation of personality profile taking into account the level of selfefficacy of the participants. As a hypothesis, based on the findings in the literature previously mentioned, it is 
expected that Conscientiousness $(+)$, Extraversion $(+)$, Agreeableness (+) and Neuroticism (-) are significant predictors of self-efficacy for professional choice. On the other hand, no significant result is expected regarding Openness. Similarly, it is expected that the same factors account for the differences in the groups with low, medium and high-efficacy. These assumptions are based on the findings in Hartman and Betz (2007), Page et al. (2008) and Rogers and Creed (2010). It is worth noting that, although the evidences of the association of Agreeableness with self-efficacy in the context of career choices is controversial, it has been decided to have them included in the hypothesis in order to test them in the context of this research, since the work of Ourique and Teixeira (2012), also conducted in Brazil, indicated certain relevance of the factor.

\section{Method}

\section{Participants}

The research was filled by 308 young adults from cities in the countryside of the São Paulo state, $57.5 \%$ female, with ages between 14 e 26 years old $(M=16.64 ; S D=$ 1.2). In regards to level of education, 48 participants $(15.3 \%)$ were in the first year of high school, 131 (42.5\%) were attending the second year and 128 (41.6\%) were in the last year of high school. Slightly over half the participants $(57.5 \%)$ were students in public schools.

\section{Instruments}

The Professional Choice Self-efficacy Scale (EAE-EP Ambiel and Noronha 2012) is composed by 47 items with 4 points Likert scale and evaluates people's beliefs in their own capacity to get involved in activities related to professional choice. The evaluation is made through four factors. These factors are: Self-Efficacy for selfappraisal, Self-Efficacy for Gathering Occupational Information, Self-Efficacy for Professional Practical Information Search and Self-Efficacy for Future Planning, in addition to a general score. The psychometric parameters were evaluated by means of evidences based on internal structure, relationship with other variables and by the Rasch model. The coefficients Cronbach's Alpha, in the general sample, vary between .79 (Future Planning) and .88 (Self-appraisal), and for the total score, the alpha was .94 .

The Factorial Personality Battery (BFP - Nunes et al. 2010) is based on the Big Five factor of personality model (Neuroticism, Conscientiousness, Agreeableness, Extraversion and Openness) and formed by 126 items, 7 points Likert scale, the psychometric parameters were verified through the collection of evidences based on the internal structure and the relation with other variables, with satisfactory levels of fidedignity, varying from .74 (Openness) and .89 (Neuroticism).

\section{Procedures}

This article is part of a bigger project that was properly submitted and approved by an ethics committee in research with human beings (CAAE: 0231.0.142.000-08). After the authorization of the schools, contacts were made with the students to explain the goals of the task as well as to send the informed consent form. The only students participating were those whose terms were handed back in signed. The collection was made in classrooms, generally conducted by two supervisors, wherein one was a psychologist and the other was a Psychology student, with the duration of approximately one hour. The instruments were applied in alternating order.

\section{Data analysis}

For the first objective of this study, a multiple regression analysis, enter method, was used. For the second, the analysis made was ANOVA, with post hoc of the Tukey test and profile analysis by repeated measures. It was also verified the effect size of the differences between groups, through $d$ Cohen (1988), wherein values up to.40 are considered minor effects, from .50 to .70 considered average effects, and as from .80 strong effects.

\section{Results}

In the first moment, the data was tested and it was verified that they met up to all requirements so as to execute the regression, regarding the normal distribution and multi-colinearity of the variables, wherein the levels of tolerance were around 0.80 and the variance inflation factor (VIF) around 1.00. For the realization of the multiple regression analysis, the factors five big factors were inserted as independent variables and as dependent variables, the factors and total score of EAE-EP. In Table 1 the final models are presented, only with the statistically significant results.

In general, it can be seen that Conscientiousness, Extraversion and Agreeableness are the main professional choice self-efficacy predictors and explained $17 \%$ of the variance in Self-appraisal, $14 \%$ in Gathering Occupational Information and $21 \%$ of the total score. For the factors Practical Professional Information Search and Future Planning, scores in Extraversion were significant predictors, along with Agreeableness and Conscientiousness, respectively.

Therefore, one can consider that the hypotheses of this study about the predictive capacity of personality factors regarding professional choice self-efficacy factors were partially corroborated, especially when it comes to Conscientiousness, Agreeableness and mainly Extraversion. 
Table 1 Multiple regression coefficients

\begin{tabular}{|c|c|c|c|c|c|}
\hline \multicolumn{2}{|l|}{ Variables } & \multirow[b]{2}{*}{ B } & \multirow[b]{2}{*}{$E P$} & \multirow[b]{2}{*}{$\beta$} & \multirow[b]{2}{*}{$R^{2}$ adj } \\
\hline Dependent & Independent & & & & \\
\hline \multirow[t]{3}{*}{ Self-Appraisal } & Extraversion & 1.40 & .29 & $.29 * *$ & .17 \\
\hline & Conscientiousness & .86 & .29 & $.17^{*}$ & \\
\hline & Agreeableness & .98 & .35 & $.17^{*}$ & \\
\hline \multirow[t]{3}{*}{ Gathering Occupational Information } & Agreeableness & 2.47 & .61 & $.25^{* *}$ & .14 \\
\hline & Conscientiousness & 1.64 & .51 & $.19^{* *}$ & \\
\hline & Extraversion & 1.17 & .51 & $.14^{*}$ & \\
\hline \multirow[t]{2}{*}{ Practical Professional Information Search } & Extraversion & 2.92 & .43 & $.39^{* *}$ & .19 \\
\hline & Agreeableness & 2.13 & .53 & $.24^{* *}$ & \\
\hline \multirow[t]{2}{*}{ Future Planning } & Conscientiousness & .68 & .19 & $.21^{* *}$ & .07 \\
\hline & Extraversion & .54 & .19 & $.17^{* *}$ & \\
\hline \multirow[t]{3}{*}{ Total Score EAE-EP } & Extraversion & 6.22 & 1.16 & $.33^{* *}$ & .21 \\
\hline & Agreeableness & 6.17 & 1.45 & $.27^{* *}$ & \\
\hline & Conscientiousness & 3.70 & 1.17 & $.18^{* *}$ & \\
\hline
\end{tabular}

${ }^{*} p<.05 ;{ }^{* *} p<.01$

However, Neuroticism, which was expected with negative valence, did not stand out. Furthermore, it should be noted that the self-efficacy factor with the highest explained variance was Self-appraisal, since it can be considered theoretically coherent, as it evaluates the belief that the person can adequately describe themselves, mainly in terms of their own personality.

Considering the second objective of this study, an analysis was carried out on the frequency of weighted scores, dividing the sample into quartiles considering the scores in EAE-EP. For the purpose of analysis, three groups were considered, namely, low self-efficacy, (G1 quartile up to $25 \%$ ); medium-efficacy (G2 - between 26 and $75 \%$ ); and high-efficacy (G3 - $76 \%$ and above). The cut-off scores for the extreme groups were $\leq 3.01$ for G1 and G3 in $\geq 3.59$ for self-evaluation; $\leq 2.82$ for G1 and G3 in $\geq 3.45$ for Occupational Information Collection; $\leq 2.64$ for G1 and G3 for $\geq 3.53$ in Practical Professional Information Search; $\leq 3.00$ for G1 and G3 for $\geq 3.62$ in future planning; and $\leq 2.94$ for $G 1$ and $G 3 \geq 3.50$ for total score.

With these data, analysis of variance (ANOVA) for personality factors according to the groups was performed. Then, post hoc Tukey analysis was requested $(p \leq 0.01)$ to establish the nature of these differences, and calculated the Cohen's $d$ coefficient to understand the effects sizes between groups. Table 2 presents this information, considering only statistically significant differences.

In this table, one can see that, just as in the analysis of predictors, Neuroticism also did not appear as a factor able to differentiate people with different levels of professional choice self-efficacy. Also there is the information that, in all cases in which the Tukey post hoc test reported the formation of subsets $(p \leq .01), \mathrm{G1}$ and G3 took the position of extreme condition groups, and G2 herein grouped together with G1, and at times with G3, in some cases was in both subsets. In specific case of Extraversion profile, all the three groups were differentiated from each other from the scores in Practical Professional Information Search.

Another important finding that Table 2 shows is related to the effects sizes of differences between groups. When the extreme groups (G1 and G3) were compared in terms of Extraversion (AA, BIP and ET) and Conscientiousness (AA, CIO, BIP, PF and ET), it turns out that Cohen's $d$ coefficients were close to .80 or higher, suggesting that in such cases, such personality traits are the ones that better distinguish between people with low and high level of self-efficacy for career choice.

Moreover, noteworthy is the fact that even in clusters that did not differ significantly, the magnitude of the effects reported that the difference between groups was large enough to conclude about differentiation, as noted in analysis involving groups of the factors Occupational Information Collection and Practical Professional Information Search with Openness. Similarly, it can be observed that groups that formed the same subset based on Tukey test but whose magnitude of the effect of their differences indicated important values, around .40 (ie, G2 and G3 of SelfAppraisal for Extraversion and Openness and G2 and G3 of Future Planning for Conscientiousness). Figure 1 allows to graphically view the personality profiles with different levels of EAE-EP total score.

Therefore, it can be considered that the hypotheses, also for the second objective of this study were partially corroborated, since Conscientiousness and Extraversion were the factors that best discriminated groups, unlike 
Table 2 Variance analysis (ANOVA) of personality factors considering the groups with different levels of self-efficacy

\begin{tabular}{|c|c|c|c|c|c|c|}
\hline & & SA & $\mathrm{OIC}$ & PPI & FP & TS \\
\hline \multirow[t]{7}{*}{$\bar{E}$} & DF & 2 & 2 & 2 & 2 & 2 \\
\hline & $\mathrm{F}$ & 19.028 & 6.835 & 25.164 & 6.308 & 16.500 \\
\hline & P & $\leq .001$ & $\leq .001$ & $\leq .001$ & .002 & $\leq .001$ \\
\hline & Tukey & $\mathrm{G} 1<\mathrm{G} 2, \mathrm{G} 3$ & $\mathrm{G} 1, \mathrm{G} 2<\mathrm{G} 2 . \mathrm{G} 3$ & $\mathrm{G} 1<\mathrm{G} 2<\mathrm{G} 3$ & $\mathrm{G} 1, \mathrm{G} 2<\mathrm{G} 2, \mathrm{G} 3$ & $\mathrm{G} 1, \mathrm{G} 2<\mathrm{G} 3$ \\
\hline & D & $\mathrm{d}_{\mathrm{G} 1, \mathrm{G} 2}=.61$ & $\mathrm{~d}_{\mathrm{G} 1, \mathrm{G} 2}=.26$ & $\mathrm{~d}_{\mathrm{G} 1, \mathrm{G} 2}=.48$ & $\mathrm{~d}_{\mathrm{G} 1, \mathrm{G} 2}=.22$ & $\mathrm{~d}_{\mathrm{G} 1, \mathrm{G} 2}=.38$ \\
\hline & & $\mathrm{d}_{\mathrm{G} 1, \mathrm{G} 3}=.98$ & $\mathrm{~d}_{\mathrm{G} 1, \mathrm{G} 3}=.54$ & $\mathrm{~d}_{\mathrm{G} 1, \mathrm{G} 3}=1.15$ & $\mathrm{~d}_{\mathrm{G} 1, \mathrm{G} 3}=.65$ & $\mathrm{~d}_{\mathrm{G} 1, \mathrm{G} 3}=.92$ \\
\hline & & $\mathrm{d}_{\mathrm{G} 2, \mathrm{G} 3}=.43$ & $\mathrm{~d}_{\mathrm{G} 2, \mathrm{G} 3}=.28$ & $\mathrm{~d}_{\mathrm{G} 2, \mathrm{G} 3}=.64$ & $\mathrm{~d}_{\mathrm{G} 2, \mathrm{G} 3}=.38$ & $\mathrm{~d}_{\mathrm{G} 2, \mathrm{G} 3}=.54$ \\
\hline \multirow[t]{7}{*}{ A } & DF & 2 & 2 & 2 & 2 & 2 \\
\hline & $\mathrm{F}$ & 4.637 & 8.843 & 4.339 & 6.614 & 5.692 \\
\hline & $P$ & .02 & $\leq .001$ & .02 & .002 & .004 \\
\hline & Tukey & - & $\mathrm{G} 1, \mathrm{G} 2<\mathrm{G} 2, \mathrm{G} 3$ & - & $\mathrm{G} 1, \mathrm{G} 2<\mathrm{G} 2, \mathrm{G} 3$ & $\mathrm{G} 1, \mathrm{G} 2<\mathrm{G} 2, \mathrm{G} 3$ \\
\hline & $\mathrm{D}$ & $\mathrm{d}_{\mathrm{G} 1, \mathrm{G} 2}=.39$ & $\mathrm{~d}_{\mathrm{G} 1, \mathrm{G} 2}=.22$ & $\mathrm{~d}_{\mathrm{G} 1, \mathrm{G} 2}=.04$ & $\mathrm{~d}_{\mathrm{G} 1, \mathrm{G} 2}=.28$ & $\mathrm{~d}_{\mathrm{G} 1, \mathrm{G} 2}=.13$ \\
\hline & & $\mathrm{d}_{\mathrm{G} 1, \mathrm{G} 3}=.37$ & $\mathrm{~d}_{\mathrm{G} 1, \mathrm{G} 3}=.60$ & $\mathrm{~d}_{\mathrm{G} 1, \mathrm{G} 3}=.42$ & $\mathrm{~d}_{\mathrm{G} 1, \mathrm{G} 3}=.65$ & $\mathrm{~d}_{\mathrm{G} 1, \mathrm{G} 3}=.50$ \\
\hline & & $\mathrm{d}_{\mathrm{G} 2, \mathrm{G} 3}=-.01$ & $\mathrm{~d}_{\mathrm{G} 2, \mathrm{G} 3}=.39$ & $\mathrm{~d}_{\mathrm{G} 2, \mathrm{G} 3}=.38$ & $\mathrm{~d}_{\mathrm{G} 2, \mathrm{G} 3}=.37$ & $\mathrm{~d}_{\mathrm{G} 2, \mathrm{G} 3}=.39$ \\
\hline \multirow[t]{7}{*}{ C } & DF & 2 & 2 & 2 & 2 & 2 \\
\hline & $\mathrm{F}$ & 18.285 & 13.175 & 9.767 & 15.286 & 11.630 \\
\hline & $P$ & $\leq .001$ & $\leq .001$ & $\leq .001$ & $\leq .001$ & $\leq .001$ \\
\hline & Tukey & $\mathrm{G} 1<\mathrm{G} 2, \mathrm{G} 3$ & $\mathrm{G} 1, \mathrm{G} 2<\mathrm{G} 2, \mathrm{G} 3$ & $\mathrm{G} 1, \mathrm{G} 2<\mathrm{G} 3$ & $\mathrm{G} 1<\mathrm{G} 2, \mathrm{G} 3$ & $\mathrm{G} 1, \mathrm{G} 2<\mathrm{G} 3$ \\
\hline & $\mathrm{D}$ & $\mathrm{d}_{\mathrm{G} 1, \mathrm{G} 2}=.68$ & $\mathrm{~d}_{\mathrm{G} 1, \mathrm{G} 2}=.34$ & $\mathrm{~d}_{\mathrm{G} 1, \mathrm{G} 2}=.13$ & $\mathrm{~d}_{\mathrm{G} 1, \mathrm{G} 2}=.59$ & $\mathrm{~d}_{\mathrm{G} 1, \mathrm{G} 2}=.33$ \\
\hline & & $\mathrm{d}_{\mathrm{G} 1, \mathrm{G} 3}=.97$ & $\mathrm{~d}_{\mathrm{G} 1, \mathrm{G} 3}=.75$ & $\mathrm{~d}_{\mathrm{G} 1, \mathrm{G} 3}=.70$ & $\mathrm{~d}_{\mathrm{G} 1, \mathrm{G} 3}=.97$ & $\mathrm{~d}_{\mathrm{G} 1, \mathrm{G} 3}=.78$ \\
\hline & & $\mathrm{d}_{\mathrm{G} 2, \mathrm{G} 3}=.30$ & $\mathrm{~d}_{\mathrm{G} 2, \mathrm{G} 3}=.40$ & $\mathrm{~d}_{\mathrm{G} 2, \mathrm{G} 3}=.52$ & $\mathrm{~d}_{\mathrm{G} 2, \mathrm{G} 3}=.41$ & $\mathrm{~d}_{\mathrm{G} 2, \mathrm{G} 3}=.44$ \\
\hline \multirow[t]{7}{*}{$\mathrm{O}$} & DF & 2 & 2 & 2 & 2 & 2 \\
\hline & $\mathrm{F}$ & 4.906 & 3.583 & 2.735 & .016 & 3.349 \\
\hline & P & .008 & .03 & .07 & .984 & .04 \\
\hline & Tukey & $\mathrm{G} 1, \mathrm{G} 2<\mathrm{G} 2, \mathrm{G} 3$ & - & - & - & - \\
\hline & D & $\mathrm{d}_{\mathrm{G} 1, \mathrm{G} 2}=.06$ & $\mathrm{~d}_{\mathrm{G} 1, \mathrm{G} 2}=.11$ & $\mathrm{~d}_{\mathrm{G} 1, \mathrm{G} 2}=.30$ & $\mathrm{~d}_{\mathrm{G} 1, \mathrm{G} 2}=.02$ & $\mathrm{~d}_{\mathrm{G} 1, \mathrm{G} 2}=.16$ \\
\hline & & $\mathrm{d}_{\mathrm{G} 1, \mathrm{G} 3}=.46$ & $\mathrm{~d}_{\mathrm{G} 1, \mathrm{G} 3}=.39$ & $\mathrm{~d}_{\mathrm{G} 1, \mathrm{G} 3}=.36$ & $\mathrm{~d}_{\mathrm{G} 1, \mathrm{G} 3}=-.02$ & $\mathrm{~d}_{\mathrm{G} 1, \mathrm{G} 3}=.42$ \\
\hline & & $\mathrm{d}_{\mathrm{G} 2, \mathrm{G} 3}=.41$ & $\mathrm{~d}_{\mathrm{G} 2, \mathrm{G} 3}=.27$ & $\mathrm{~d}_{\mathrm{G} 2, \mathrm{G} 3}=.05-$ & $\mathrm{d}_{\mathrm{G} 2, \mathrm{G} 3}=-.03$ & $\mathrm{~d}_{\mathrm{G} 2, \mathrm{G} 3}=.25$ \\
\hline
\end{tabular}

Note: SA: self appraisal, OIC: Occupational Information Collection; PPI: Practical Professional Information Search; FP: Future Planning; TS: Total Score in EAE-EP; E: Extraversion; A: Agreeableness; $C$ : conscientiousness; O: Openness

Neuroticism, which, once again, did not show significance in the analyses. It is worth mentioning that although Agreeableness and Openness have differentiate groups, the observed effect size was never high. Moreover, another aspect worth mentioning regards the differentiation between the groups of the Practical Professional Information Search factor as compared to Extraversion. Whereas people with high scores in this last factor of EAE-EP tend to have high level of beliefs in their capacity to get information about courses or professions from interpersonal contacts, it seems important from a theoretical point of view that all groups have been differentiated from each other with satisfactory effect sizes.

\section{Discussion}

This study had two distinct goals, although interconnected, relating personality and professional choice selfefficacy. The first was to assess the predictive power of personality in relation to self-efficacy and the second intended to investigate the personality profile of people with different levels of the second construct.

On the first goal, as previously described, the hypotheses were partially corroborated. It could be observed that Extraversion and Conscientiousness personality traits are very important in predicting the professional choice self-efficacy in their various aspects, as already described in the literature, for example, by Hartman and Betz (2007), Page et al. (2008) and Rogers and Creed 


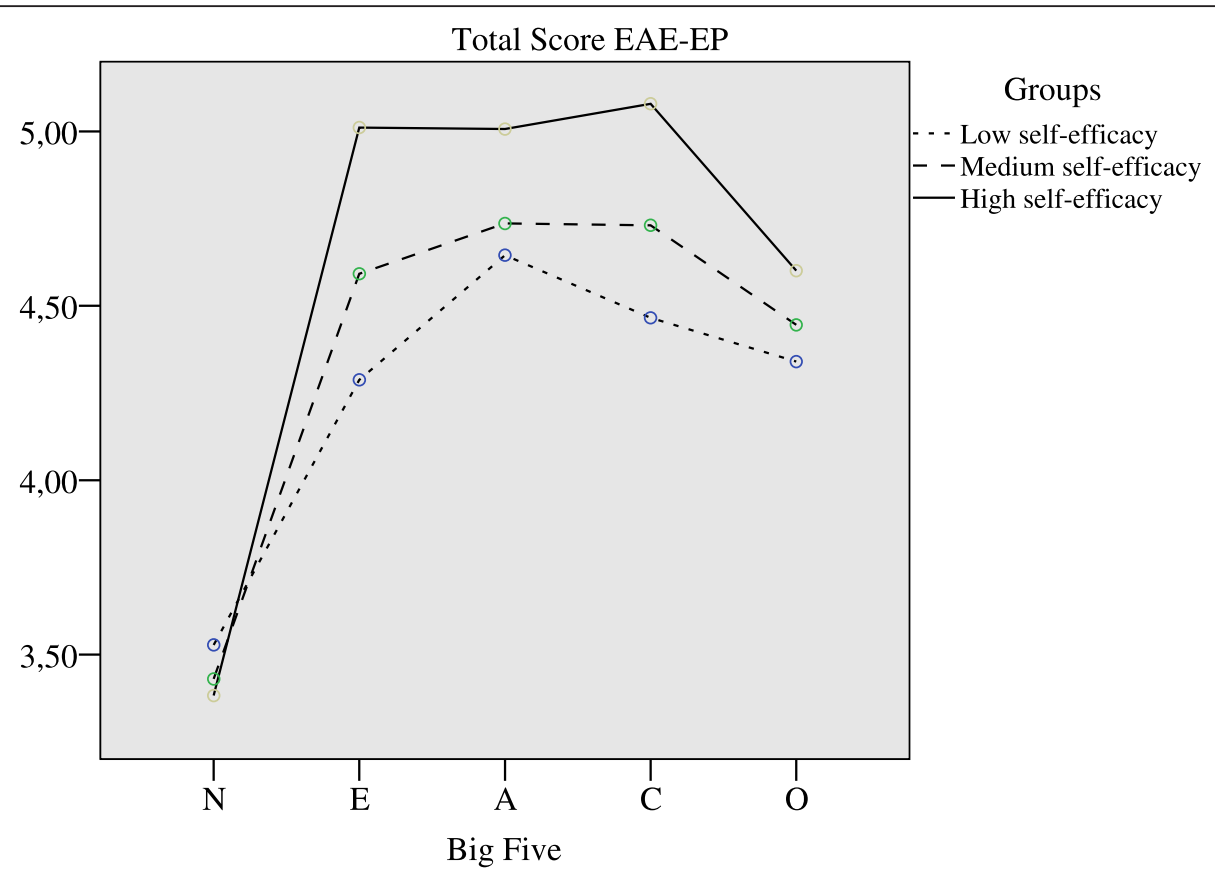

Fig. 1 Personality profile for different levels of EAE-EP total score

(2010). Moreover, Agreeableness was also shown as an important factor in self-efficacy explanation, a fact that is in line with the findings of Jin et a.l (2009) and especially of Ourique and Teixeira (2012). Furthermore, to confirm the hypotheses suggested, the factor Openness did not show significance as a predictor of self-efficacy. Possibly this has taken place because of the nonspecific nature of the Openness trait, that is, by the factor's own condition regarding the wide field of interests of people with a high level of Openness, as opposed to the aspect of specificity of self-efficacy. However, unlike what was hypothesized based on Hartman and Betz (2007), Page et al. (2008) and Rogers and Creed (2010), Neuroticism was not a significant predictor of any factor of self-efficacy.

Thus, we can understand that, as described by Lent et al. (1994) and Larson and Borgen (2006), personality seems to have a prominent importance the process of formation of self-efficacy beliefs. Although this study has not been done in a longitudinal perspective, not allowing conclusions regarding the cause and effect between the constructs, it can be observed that characteristics such as organization, persistence, motivation, responsibility to achieve objectives, level and type of social interaction in terms of the amount and intensity (Nunes et al. 2010) are characteristics that explained an important part of capacity beliefs to engage in professional choice tasks, in all its different factors.

More specifically, the second objective of this study allowed to identify the personality profile of people with different levels of self-efficacy. This procedure is interesting as it allows reflection on the role of personality factors in the behavior of groups that, at the time of the survey, reported different levels in EAE-EP factors. It is worth mentioning that in the division of the groups, we can observe a tendency to higher scores, closer to the top of the scores on the factors, that is, a tendency to above the mid-point scores. This is clear when we take notice that the lower cut score to form the group with low self-efficacy was 2.64 in the Practical Professional Information Search factor, whereas in Self-Appraisal the highest score was observed (3.01) in a scale ranging from 1 to 4 . In addition, the difference between the groups with low and high self-efficacy was never even equal to 1 point, and the closer it was observed was in Practical Professional Information Search factor, with a difference of 89 on a weighted average.

However, despite the small differences in scores, it was possible to discriminate between groups in terms of their personality characteristics. In other words, small modulations in EAE-EP scores are related to major differences in the personality profile. Again, Extraversion, Councientiousness and Agreeableness were the factors better able to identify people with low, medium and high self-efficacy, always in the sense that the group with higher scores on the EAE-EP also obtained higher scores in these personality factors.

Specifically, in Self-Appraisal and Practical Professional Information Search, Extraversion and Councientiousness were the personality traits that best differentiate the groups, while in Gathering Occupational Information and 
Future Planning, Agreeableness is added to the previous two factors. It is noteworthy that the largest effect size was observed between the groups with low and high self-efficacy for Practical Professional Information Search regarding the Extraversion factor. This result is highly consistent from a conceptual point of view, as this factor of EAE-EP regards the sense of ability to get information about the professions, courses and the labor market through interpersonal relationships, such as interviews and visits (Ambiel and Noronha 2012). It is, therefore, interesting that just the personality characteristics related to one's ability to expose oneself and start conversations, even with strangers (Nunes et al., 2010) be so markedly a differential in the level of self-efficacy.

Therefore, as in the first goal, the hypothesis related to the second goal was also partially supported, and in the same way the previous one had been. Again, there was no relevance of the Neuroticism factor to explain the differences between the levels of self-efficacy as hypothesized, but Agreeableness played an important role, unlike expected.

Overall, the results of this study showed that there is an important relationship between personality and selfefficacy for professional choice. Moreover, the results indicate the explanatory capacity of one over the other and shed light on the features that stand out when comparing extreme groups in scores of EAE-EP.

\section{Conclusion}

In conclusion, we can claim that the objectives of the present result have been reached, once hypothesis were partially corroborated. Accordingly, the main contribution of this study was to draw the personality profile of people with different levels of self-efficacy for professional choice. This is important, once studies, both in the Brazilian as well as in the foreign scenario have focused on correlational methodologies to verify the common points among the constructs hereby evaluated, which allows the establishment of a relation pattern between both, but not to specify the typical characteristics of the groups.

In this sense, such result may be considered useful in the practice of professional and career counseling, as it may help counselors to define intervention strategies according to the information from the evaluations, in addition to more comprehensive prognosis. We must consider that, as preconized by Bandura (1986), selfefficacy is one of the main precursors of behavior and, by associating it with personality, that is, the typical behavior patterns that people claim to have, the information generated by this study must be taken into account in the interpretation of the instruments applied in this context.
Some limitations must also be taken into consideration. Firstly, the teenagers participating in this study were not going through any type of vocational counseling intervention. Moreover, important variables in the context such as indecision or exploratory professional behavior were not taken into account. Therefore, this limitation is applied to the comprehension of results, which must be understood as personality profiles of young high school students, without taking into consideration their necessity of undergoing such process or not.

This aspect may have influenced in the composition of the groups, once, for instance, the negative and moderate correlation standard between self-efficacy and indecision is already known. (Gati et al. 2013). Therefore, in terms of future studies, this study may be replicated with clinical samples, verifying, for example, the role of personality intermediation regarding groups with different levels of self-efficacy and the success rate of interventions in order to minimize indecision.

\section{Competing interests}

The authors declare that they have no competing interests.

\section{Authors' contributions}

All authors read and approved the final manuscript.

Received: 9 March 2016 Accepted: 7 April 2016

Published online: 22 April 2016

\section{References}

Ambiel RAM, Noronha APP. Escala de Autoeficácia para Escolha Profissional: manual técnico. São Paulo: Casa do Psicológo; 2012.

Ambiel RAM, Noronha APP, Carvalho LF. Analysis of the professional choice self-efficacy scale using Rasch-Andrich rating scale model. Int J Educ Vocational Guid. 2015;15(3):205-19.

Ambiel RAM, Noronha APP, Nunes MFO. Interesses profissionais e personalidade: um aporte para a integração dos construtos. Avaliação Psicológica. 2012;11(2):191-201.

Bandura A. Self-efficacy: Toward a unifying theory of behavior change. Psychol Rev. 1977;84:191-215. doi:10.1037/0033-295X.84.2.191.

Bandura A. Social foundations of thought and action: A social cognitive theory. Englewood Cliffs, NJ: Prentice-Hall; 1986.

Betz NE, Taylor KM. Career Decision Self-Efficacy Scale: manual and sampler set. EUA: Mind Garden; 2012.

Breeding RR. Empowerment as a Function of Contextual Self-Understanding The Effect of Work Interest Profiling on Career Decision Self-Efficacy and Work Locus of Control. Rehabil Couns Bull. 2008;51(2):96-106. doi:10.1177/ 0034355207311346

Carvalho LF, Souza BDB, Primi R. Psychometric properties of the revised conscientiousness dimension of Inventário Dimensional Clínico da Personalidade (IDCP). Trends Psychiatry Psychother. 2014;36(1):23-31. doi:10.1590/2237-6089-2013-0024.

Chaney D, Hammond MS, Betz NE, Multon KD. The Reliability and Factor Structure of the Career Decision Self-Efficacy Scale-SF With African Americans. J Career Assess. 2007;15(2):194-205. doi:10.1177/1069072706298020.

Choi BY, Park H, Yang E, Lee SK, Lee Y, Lee, SM. Understanding Career Decision Self-Efficacy A Meta-Analytic Approach. Journal of Career Development. 2012;39(5):443-460. doi:10.1177/0894845311398042.

Costa PT, McCrae RR. Normal personality assessment in clinical practice: the NEO Personality Inventory. Psychological Assessment. 1992;4(1):5.

Cohen J. Statistical power analysis for the behavioral sciences (2nd ed.). Hillsdale, NJ: Lawrence Earlbaum Associates; 1998.

Creed PA, Patton W, Watson M. Cross-cultural equivalence of the Career Decision-making Self-efficacy scale - Short Form: An Australian and South 
African comparison. J Career Assess. 2002;10:327-42. doi:10.1177/ 10672702010003004.

Cupani M, Pérez ER. Metas de eléccion de carrera: contribución de de los interesses vocacionales, la autoeficacia y los rasgos de personalidad. Interdisciplinaria. 2006;23(1):81-100.

Gati I, Tehila R, Vertsberger D. Preparing young veterans for civilian life: The effects of a workshop on career decision-making difficulties and self-efficacy. Journal of Vocational Behavior. 2013;83(3):373-85. doi:10.1016/j.jvb.2013.06.001.

Hackett G, Betz NE. A self-efficacy approach to the career development of women. Journal of Vocational Behavior. 1981;18:326-36. doi:10.1016/00018791(81)90019-1.

Hampton NZ. A psychometric evaluation of the career decision self-efficacy scale-short form in Chinese high schools students. Journal of Career Development. 2006;33(2):142-55. doi:10.1177/0894845306293540.

Hartman RO, Betz NE. The Five-Factor Model and Career Self-Efficacy: general and domain-specific relationships. J Career Assess. 2007;15(2):145-61. doi:10.1177/1069072706298011.

Isik E. The relationship of career decision self-efficacy, trait anxiety, and affectivity among undergraduate students. Psychol Rep: Human Resour Market. 2012:111(3):805-13. doi:10.2466/01.09.10.PR0.111.6.805-813.

Jin L, Watkins D, Yues M. Personality, career decision self-efficacy and commitment to the career choices process among Chinese graduate students. J Vocat Behav. 2009;74:47-52. doi:10.1016/j.jvb.2008.10.002.

Larson LM, Borgen FH. Do personality traits contribute to vocational self-efficacy? J Career Assess. 2006;14(3):295-311. doi:10.1177/1069072706286446.

Lent RW, Brown SD, Hackett G. Towards a unifying social cognitive theory of career and academic interests, choice and performance. J Vocat Behav. 1994;45(1):79-122. doi:10.1006/jvbe.1994.1027.

Luzzo DA. Reliability and validity testing of the career decision-making selfefficacy scale. Meas Eval Couns Dev. 1993;26(2):137-42.

Miguel JP, Silva JT, Prieto G. Career Decision Self-Efficacy Scale - Short Form: A Rasch analysis of the Portuguese version. J Vocat Behav. 2013;82(2):116-23. doi:10.1016/j.jvb.2012.12.001

Nauta MM. Career Interests, Self-Efficacy, and Personality as Antecedents of Career Exploration. J Career Assess. 2007;15(2):162-80. doi:10.1177/ 1069072706298018

Nunes CHSS, Hutz CS, Nunes MFO. Bateria Fatorial de Personalidade: manual técnico. São Paulo: Casa do Psicólogo; 2010.

Nunes MFO, Noronha APP. Escala de Autoeficácia para Atividades Ocupacionais: Construção e estudos exploratórios. Paidéia. 2008;18(39):111-24. doi:10.1590/S0103-863X2008000100011.

Nunes MFO, Noronha APP. Relações entre interesses, personalidade e habilidades cognitivas: um estudo com adolescentes. Psico-USF. 2009;14(2):131-41. doi:10.1590/\$1413-82712009000200002.

Nunes MFO, Noronha APP. Associações entre Auto-Eficácia para Atividades Ocupacionais e Interesses em Adolescentes. Psicologia: Reflexão e Crítica. 2011;24(1):1-9. doi:10.1590/S0102-79722011000100002.

Ourique LR, Teixeira MAP. Autoeficácia e personalidade no planejamento de carreira de universitários. PsicoUSF. 2012;17(2):311-21. doi:10.1590/S141382712012000200015.

Page J, Bruch MA, Haase RF. Role of perfectionism and Five-Factor model traits in career indecision. Pers Individ Differ. 2008:45:811-5. doi:10.1016/j.paid.2008. 08.013 .

Peterson SL, delMas RC. The component structure of Career Decision-making Self-efficacy for underprepared college students. J Career Dev. 1998;24(3):209-25. doi:10.1177/089484539802400304.

Pulver A, Allik J, Pulkkinen L, Hamalainen M. A Big Five personality inventory in two non-IndoEuropean languages. European Journal of Personality. 1995;9:109-124.

Ramírez MC, Canto JE. Development and evaluation of a scale for measuring self-efficacy in career choice in Mexican students. Electron J Res Educ Psychol. 2007:5(1):37-56.

Reese RJ, Miller CD. Effects of a University Career Development Course on Career Decision-Making Self-Efficacy. J Career Assess. 2006;14(2):252-66. doi:10.1177/1069072705274985.

Rogers ME, Creed PA. A longitudinal examination of adolescent career planning and exploration using a social cognitive career theory framework. J Adolescence. 2010;34(1):163-72. doi:10.1016/j.adolescence.2009.12.010.
Silva SS, Maia AC. Psychological and health comorbidities before and after bariatric surgery: a longitudinal study. Trends Psychiatry Psychother. 2013;35(4):264-71. doi:10.1590/2237-6089-2013-0007.

Soto CJ, John OP, Gosling SD, Potter J. Age differences in personality traits from 10 to 65: BigFive domains and facets in a large cross-sectional sample. Journal of Personality and Social Psychology. 2011;100:330-348.

Srsic CS, Walsh WB. Person-enviroment congruence and career self-efficacy. J Career Assess. 2001;9(2):203-13. doi:10.1177/106907270100900207.

Stacy MEW. Influences of selected demographic variables on the Career Decision-making Self-efficacy of college seniors. Louisiana State University: Tese de doutorado; 2003.

Taylor KM, Betz NE. Applications of self-efficacy theory to the understanding and treatment of career indecision. J Vocat Behav. 1983;22(1):63-81. doi:10.1016/0001-8791(83)90006-4.

Turner BM, Betz NE, Edwards MC, Borgen FH. Psychometric examination of an Inventory of Self-Efficacy for the Holland Vocational Themes using Item Response Theory. Meas Eval Couns Dev. 2010;43(3):188-98. doi:10.1177/ 0748175610384810

Watson MB, Brand HJ, Stead GB, Ellis RR. Confirmatory factor analysis of the Career Decision-Making Self-efficacy Scale among south African university students. J Ind Psychol. 2001;27(1):43-6. doi:10.4102/sajip.v27i1.774.

Wille B, De Fruyt F. Vocations as a Source of Identity: Reciprocal Relations Between Big Five Personality Traits and RIASEC Characteristics Over 15 Years. J Appl Psychol. 2014;99(2):262-81. doi:10.1037/a0034917.

Woods SA, Lievens F, De Fruyt F, Willw B. Personality across working life: The longitudinal and reciprocal influences of personality on work. J Organ Behav. 2013;34:S7-25. doi:10.1002/job.1863.

Zacher H. Career adaptability predicts subjective career success above and beyond personality traits and core self-evaluations. J Vocat Behav. 2014;84(1):21-30. doi:10.1016/j.jvb.2013.10.002.

\section{Submit your manuscript to a SpringerOpen ${ }^{\circ}$ journal and benefit from:}

- Convenient online submission

- Rigorous peer review

- Immediate publication on acceptance

- Open access: articles freely available online

- High visibility within the field

- Retaining the copyright to your article

Submit your next manuscript at springeropen.com 